\title{
Stressors, social support, and effects upon performance in golf
}

\author{
TIM REES ${ }^{1}$, LEW HARDY ${ }^{2}$, \& PAUL FREEMAN ${ }^{1}$ \\ ${ }^{1}$ Exercise and Sport Psychology Unit, School of Sport and Health Sciences, University of Exeter, Exeter and ${ }^{2}$ School of Sport, \\ Health and Exercise Sciences, University of Wales Bangor, Bangor, UK
}

(Accepted 27 February 2006)

\begin{abstract}
In this study, we extended the work of Rees and Hardy (2004) by examining the main and stress-buffering effects of social support upon sports performance in a different context, using a different outcome measure, and a specific time-frame. A high-level performance sample of 117 male golfers (mean age 24.8, $s=8.3$ ) completed measures of social support and stressors before competitions. Performance outcome was recorded. Moderated hierarchical regression analyses revealed significant $(P<0.05)$ main effects for stressors upon performance in 8 of the 11 models tested $\left(R^{2}=0.08-0.21\right)$. Over and above the variance accounted for by stressors, there were significant $(P<0.05)$ main effects for social support upon performance in all models tested $\left(\Delta R^{2}=0.10-0.24\right)$. In all models, stressors were associated with worse performance, whereas social support was associated with better performance. There were no significant interactions (stress-buffering effects). Main effects for social support upon performance suggest that social support may have aided performance directly, regardless of the level of stress.
\end{abstract}

Keywords: Social support, performance

\section{Introduction}

Although I. G. Sarason, Sarason and Pierce (1990) proposed that social support might affect sports performance, there has been no explicit attempt to test this proposal. A few researchers have noted social support as an important resource within a performance context (e.g. Gould, Guinan, Greenleaf, Medbery, \& Peterson, 1999; Holt \& Hogg, 2002; Rees \& Hardy, 2000), and recently some (Rees \& Hardy, 2004; Rees, Ingledew, \& Hardy, 1999) have used process-related performance measures. Using a high-level (regional to international standard) sample of tennis players, Rees and Hardy (2004) found evidence for main effects of social support and interactive effects of social support and stressors upon processes underlying performance. The main effects implied that social support positively influenced performance, regardless of the level of stress. The interactive effects were explained in terms of stress-buffering (for reviews, see Cohen, 1988; Cohen, Underwood, \& Gottlieb, 2000; B. R. Sarason, Sarason, \& Pierce, 1990a; Veiel \& Baumann, 1992): higher levels of social support protected tennis players from the harmful effects of stress upon performance, but social support was relatively unimportant for those not experiencing stress. As high-level sport is characterized by a demand to perform well when under intense pressure (Jones, 1995), studies of high-level performance are particularly notable. The purpose of the present study was to extend the work of Rees and Hardy (2004) by examining the impact of social support on performance using a sample of high-level golfers. This study also addressed Rees and Hardy's recommendations to conduct studies in different contexts, using different outcome measures and specific timeframes.

Although Rees and Hardy (2004) assessed perceived social support, the present study assessed the influence of received support upon performance. This distinction is highlighted, because perceived support (often referred to as the perception of available support) and received support (often referred to as enacted support) are considered separate constructs (Dunkel-Schetter \& Bennett, 1990; Helgeson, 1993; Wethington \& Kessler, 1986). The importance of receiving social support has been implicated in relation to dealing with competitive stress (Crocker, 1992), slumps in performance (Madden, Kirkby, \& McDonald, 1989), and burn-out (Gould, Tuffey, Udry, \& Loehr, 1996), and the recommendations

Correspondence: T. Rees, Exercise and Sport Psychology Unit, School of Sport and Health Sciences, University of Exeter, St Luke's Campus, Heavitree Road, Exeter EX1 2LU, UK. E-mail: tim.j.rees@exeter.ac.uk 
from the sport psychology literature are that sportspeople should be encouraged to be proactive in harnessing social support from those around them (Gould, Jackson, \& Finch, 1993a; Hardy \& Crace, 1991; Richman, Hardy, Rosenfeld, \& Callanan, 1989; Rosenfeld \& Richman, 1997). Furthermore, although empirically it is perceived support that has been most consistently linked with the stressbuffering hypothesis (Cohen, 1988; Cohen, Gottlieb, \& Underwood, 2000; Cohen \& Wills, 1985; Wills \& Shinar, 2000), theoretically both perceived and received support should aid stress-buffering (Lakey \& Cohen, 2000). For example, the perception that support is available if needed might lead to benign appraisal of the stressful event or better coping; the receipt of support might lead to a reduction in the impact of the stressor due to a direct transfer of resources (e.g. giving financial aid), or encouragement of more effective coping behaviours. These coping behaviours could also influence subsequent reappraisal of the stressor.

This buffering role of social support should not detract from its equally important role as a main effect (Wheaton, 1985). Main effects imply that social support could play an important role in influencing outcomes, either directly or via intermediate mechanisms (see Lakey \& Cohen, 2000). For example, social support could influence performance by providing advice about tactics and game plans, or by increasing positive affect, leading to a greater likelihood of experiencing flow states (cf. Cohen, 1988; Rees et al., 1999). The normal procedure for testing stress-buffering effects is moderated hierarchical regression analysis (Cohen \& Wills, 1985). This incorporates tests for both main effects (of stress and social support) and stressbuffering effects (interaction of stress and social support). In the absence of stress-buffering effects, main effects should be more closely examined. For example, Wheaton (1985) demonstrated that significant main effects for stress and support could be described as an independent distress deterrent model. In this case, stress and social support exert separate and opposite effects on outcomes (e.g. performance), with social support counteracting the negative effect of stress (Wheaton, 1985).

Before testing main effect and stress-buffering models, Rees and Hardy (2004) constructed and refined their measurement of the key social support variables. The purpose of this was to ensure contextspecific and accurate measurement of social support, not to develop and validate a scale. This same strategy was used in the present study, and follows two recommendations from the social support literature: (a) social support measures should be relevant to the situational context in which they are being used, and (b) social support researchers should write new items to capture specific aspects of the support needs of the target population (Bianco \& Eklund, 2001; House \& Kahn, 1985; Wills \& Shinar, 2000). This is akin to the measurement strategy within self-efficacy research (Bandura, 1997), for which it has been argued a "one-measure-fits-all" approach has only limited explanatory and predictive value. Furthermore, because of problematic issues of construct validity and content relevance in sport of the many existing social support measures (Rees \& Hardy, 2000; Rees, Hardy, Ingledew, \& Evans, 2000), measurement in the present study was guided by the insights of high-level performers regarding their experiences of social support (Rees \& Hardy, 2000).

In line with the recommendations of Rees and Hardy (2000), four dimensions of sport-relevant social support were assessed: emotional, esteem, informational, and tangible support. Emotional support relates to being "there" for comfort and security, leading to a person feeling loved and cared for. Esteem support relates to bolstering a person's sense of competence or self-esteem. Informational support relates to providing advice or guidance. Tangible support relates to providing concrete instrumental assistance (Cutrona \& Russell, 1990). Three stressors were chosen for their particular relevance to golf, an individual and highly technical sport. These stressors were chosen to reflect competition and noncompetition sources of stress (e.g. Gould, Jackson, \& Finch, 1993b; Hanton, Fletcher, \& Coughlan, 2005; Scanlan, Stein, \& Ravizza, 1991): "technical problems with your game," "personal problems", and "competition pressure". Both technical problems with your game (re-worded to be relevant to golf) and competition pressure had figured prominently in the study of Rees and Hardy (2004). The stressor, personal problems, was included in light of the comments of golf tour professionals in McCaffrey and Orlick (1989), who indicated that their personal life strongly affected how they played. This same observation has been made in psychological consultancy work with golfers by the authors of the present study.

The dependent variable was a competition outcome index of golf performance (an objective performance measure, explained in the Methods section, and hereafter termed GPI). Rees and Hardy (2004) used self-report assessments of processes underpinning performance. Their approach to performance assessment followed suggestions from sport psychology to include process measures that may reflect the task complexity of different sports (e.g. Gould, Petlichkoff, Simons, \& Vevera, 1987). As Weinberg (1990) had noted, focusing solely on performance outcome (e.g. winning versus losing) does not necessarily reflect how well an individual 
has performed - a sportsperson may perform well one day, but lose to a better opponent. Conversely, he or she may perform poorly, but win an easy contest. A key concern with the self-report approach, however, is potential confounders (Barrera, 1986). For example, social support might be caused by performance, or results may be prone to third variable issues, such as negative affectivity (Watson \& Pennebaker, 1989). These concerns also apply to general (social) psychology, in which the majority of social support studies focus primarily upon subjective judgements of outcome (e.g. self-report measures of mental health, anxiety, and depression). The purpose of the present study was therefore to examine the impact of social support upon objective performance outcome using a sample of high-level golfers in a naturalistic setting.

Specification of models was guided by the optimal matching hypothesis, whereby specific types of social support were carefully matched to the potential demands elicited by specific stressors (Cutrona \& Russell, 1990; Lakey \& Cohen, 2000; Wills \& Shinar, 2000). In this respect, we employed three strategies. First, we considered the relative controllability or uncontrollability of the stressors (Cutrona \& Russell, 1990): uncontrollable events lead to a need for forms of social support that foster emotion-focused forms of coping (emotional and esteem support); controllable events lead to a need for forms of social support that foster problem-focused coping (informational and tangible support). We should note here that some authors have questioned the utility of such a division of coping behaviours (Leventhal, Suls, \& Leventhal, 1993). In practice, specific forms of social support do not exclusively foster either emotion- or problemfocused coping, but can foster both (Cutrona \& Russell, 1990). Nonetheless, the use of problemfocused forms of coping in the face of uncontrollable stressors and the use of emotion-focused forms of coping in the face of controllable stressors can increase psychological distress (cf. Aldwin, 1994). Second, the content of the items on the support scales was carefully matched to the stressors. Third, as recommended by Wills and Shinar (2000), we made use of the authors' knowledge of golfers derived from previous psychological consultancy work.

\section{Models and hypotheses}

The stressor, technical problems with your game, was considered relatively controllable: technical problems with your game might be solved. For dealing with this stressor, problem-focused forms of coping were therefore hypothesized to be most appropriate. These include both informational support (such as someone to help put things in perspective) and tangible support (such as someone helping to set up sessions in practice). The stressor, personal problems, was considered a relatively uncontrollable environmental stressor: emotionfocused forms of coping were therefore hypothesized to be most appropriate. These include both emotional support (such as someone to take the golfer's mind off things) and esteem support (such as encouragement). Competition pressure was considered a relatively uncontrollable environmental stressor, for which emotion-focused forms of coping were hypothesized to be most appropriate. Each of these stressor-support combinations was specified in a model in relation to GPI. Through this process, six models were specified:

- Model 1: the interaction of technical problems with your game and informational support upon GPI.

- Model 2: the interaction of technical problems with your game and tangible support upon GPI.

- Model 3: the interaction of personal problems and emotional support upon GPI.

- Model 4: the interaction of personal problems and esteem support upon GPI.

- Model 5: the interaction of competition pressure and emotional support upon GPI.

- Model 6: the interaction of competition pressure and esteem support upon GPI.

It was hypothesized that main effects for stressors upon performance would be associated with increases in GPI (for GPI, lower scores represent better performance; higher scores represent poorer performance). It was also hypothesized that main effects for social support upon performance would be associated with decreases in GPI. Interactive effects would be explained in terms of stress buffering and would be demonstrated by the following: the detrimental effects of increases in stressors upon performance would be reduced for those with high social support compared with those with low social support.

\section{Methods}

\section{Participants}

The participants were 117 male British highperformance amateur golfers (mean age 24.8 years, $s=8.3$ ) with handicaps ranging from +2 (national/ international standard) to 6 (strong club player). The golf handicap system runs from " + " numbers (the best players) through " 0 " to " 28 " (poorer players). The number in each handicap band was as follows: $+2 \quad(n=3) ; \quad+1 \quad(n=7) ; 0 \quad(n=13) ; 1 \quad(n=16) ;$ $2 \quad(n=13) ; 3 \quad(n=14) ; 4 \quad(n=17) ; 5 \quad(n=17) ;$ $6(n=17)$. 


\section{Procedures}

The study was approved by the ethics committee of the School of Sport and Health Sciences, University of Exeter, and participants provided informed consent. Recruitment of participants was opportunistic (convenience sample) but spread across various golf courses in the South-East region of England on the practice days preceding major competitions. Participants completed measures of social support and stressors in the 2 days preceding major competitions; after competitions, participants' competition scores were recorded. Competitions were held over a maximum of 2 days, ranging from one to four rounds of golf.

\section{Measures}

Stressors. The three perceived stressors - technical problems with your game, personal problems, and competition pressure - were used to generate singleitem measures of potential stressors. The measure asked respondents, "Bearing the upcoming competition in mind, please indicate to what extent you have experienced these stressors over the past week ...,", with response options ranging on a 5-point scale from 1 ("not at all") to 5 ("a lot").

Social support. Social support was assessed using a 21-item self-report questionnaire designed for this study. The items were derived from statements made by high-level sportspeople about their social support experiences (Rees \& Hardy, 2000). The measure asked respondents, "In the past week, to what extent has someone ...", with response options ranging on a 5-point scale from 1 ("not at all") to 5 ("a lot"). The 21 items represented the four primary dimensions (emotional, esteem, informational, and tangible support) identified by Rees and Hardy. The questionnaire contained six emotional items, six esteem items, five informational items, and four tangible items. Evidence that the four dimensions underpin the items has previously been demonstrated through confirmatory factor analysis. Rees and Hardy (2004) reported adequate fit statistics $\left(\chi^{2}(98)=152.37, P=0.00\right.$, root mean square error of approximation $=0.06$, standardized root mean square residual $=0.07$, comparative fit index $=0.94$ ) and reliability coefficients $(0.73-0.89)$ for the fourfactor model.

In the present study, not every item that could have been derived from the study of Rees and Hardy (2000) was used. The 21 items were chosen for their relevance to golfers and their potential to be matched with the stressors. The criteria for inclusion of items were as follows: (a) the stressors were first chosen for their relevance to golfers and their potential influence on performance, and (b) social support items were then selected for their potential to be matched with those stressors. Before data collection, all three authors scrutinized the items making up each scale. Another two independent researchers within the School of Sport and Health Sciences at the University of Exeter (one psychologist and one sociologist) correctly assigned $100 \%$ of the items to their social support dimensions. All the items (and all other items in this study) were also scrutinized for relevance and representativeness by one golf teaching professional, two England squad members (with +3 handicaps), one competitor in national competitions (+1 handicap), and two strong club golfers (3 handicap).

Performance. Performance was assessed by GPI. Initially, golfers' nett competition scores were calculated as number of shots taken minus handicap. Because various competitions were used, on different courses, on different days, and with differing weather conditions, a procedure was also used to standardize nett scores across these conditions: this was nett scores minus a value for competition scratch score. The standard scratch score is a standard score allotted to an 18-hole golf course, and is the score that a scratch player (zero handicap) would be expected to return in ideal conditions over a measured course; it may differ from the par of the course. The competition scratch score is the adjustment that may be necessary to the standard scratch score to take account of weather and course conditions; it is the standard scratch score after it has been adjusted due to current playing conditions, using scores returned in the competition. The GPI is the nett score minus competition scratch score. For this study, lower scores for GPI represent fewer shots taken; lower scores for GPI therefore represent better performance. To demonstrate the calculation of GPI, let us consider one player as an example. Player A shot 76 in a competition. Player A had a handicap of 3 , and therefore his nett score was 73 (76-3). The competition scratch score for the competition was 72. Player A's GPI would be calculated by subtracting 72 (the competition scratch score) from 73 (nett score), which would give a GPI of +1 . As competitors completed between one and four rounds of golf, scores relative to the competition scratch score were averaged across rounds, to give the equivalent of a one-round score.

\section{Analyses}

The initial phase of analysis involved refinement of the measure of social support using confirmatory factor analysis with maximum likelihood estimation (Biddle, Markland, Gilbourne, Chatzisarantis, \& 
Sparkes, 2001; Jöreskog \& Sörbom, 1993; Schutz \& Gessaroli, 1993). The sequential model testing approach recommended by Jöreskog (1993, p. 313) and outlined in Biddle et al. (2001, p. 785) was employed. This involved three stages. First, tests of separate single-factor models corresponding to individual subscales were performed. The purpose of this was to assess the convergent validity of the items making up each subscale. Second, tests of each pair of subscales were performed, combining them in two-factor models. The purpose of this was to identify any ambiguous items. Based upon the diagnostic information from the single-factor and the two-factor stages, items were deleted from each subscale. Finally, all factors were included in the full models.

For all models, the following diagnostic information was used to aid the process of scale refinement, item deletion, and further model testing: the goodness of fit of the models, the completely standardized factor loadings, the standardized residuals, and the modification indices for the covariances of the measurement errors (e.g. Jöreskog \& Sörbom, 1993). The goodness of fit of the models was tested using the chi-square likelihood ratio statistic $\left(\chi^{2}\right)$, root mean square error of approximation (RMSEA: Steiger, 1990) and its associated $P$-value (for RMSEA < 0.05), standardized root mean square residual (SRMR), comparative fit index (CFI: Bentler, 1990), and non-normed fit index (NNFI: Tucker \& Lewis, 1973). The $\chi^{2}$ statistic is generally regarded as an initial indicator of model fit, such that a small $\chi^{2}$ corresponds to a good fit, and a large $\chi^{2}$ corresponds to a poor fit (Jöreskog \& Sörbom, 1993). Although there is no accepted criterion, the $\chi^{2}$ /degrees of freedom ratio may also provide a further standard by which to judge the size of the $\chi^{2}$ statistic. $\mathrm{Hu}$ and Bentler's (1999) recommendations for fit were used: namely, that SRMR values close to 0.08 , RMSEA values close to 0.06 , and CFI and NNFI values close to 0.95 represented a good fit.

Moderated hierarchical regression analysis (Biddle et al., 2001; Jaccard, Turrisi, \& Wan, 1990) was used to examine the effects of social support dimensions and stressors upon GPI. For the hypothesized models, the independent variables were entered hierarchically in a three-step process, corresponding to the testing of the stress-buffering hypothesis (Baron \& Kenny, 1986; Cohen \& Wills, 1985), and based upon theoretical supposition. First, the stressor was entered. Second, the social support dimension was entered. Third, the product of the stressor and the social support dimension (the interaction term, relating to whether social support has moderated the effect of the stressor on performance) was entered. The significance of increments in explained variance in performance over and above the variance accounted for by those variables already entered into the equation, as well as the sign of the regression coefficients, was then assessed at each step. In line with Jaccard and colleagues' recommendations, the independent variables were standardized before entry. An alpha level of 0.05 was used for all statistical tests.

\section{Results}

\section{Social support measure}

At the single-factor stage, and based upon the diagnostic information outlined in the Methods section, the emotional, esteem, and informational support dimensions were reduced to four-item subscales, and the tangible support dimension was reduced to a three-item subscale. For all single- and two-factor models, $\chi^{2}$ values relative to degrees of freedom were less than 2 and non-significant, and all other values met the criteria for fit of $\mathrm{Hu}$ and Bentler (1999). For the full model, the $\chi^{2}$ statistic $\left(\chi^{2}\right.$ $(84)=111.69, P=0.02)$ relative to degrees of freedom was less than 2, the RMSEA was low enough (0.05), with a non-significant test for close fit $(P=0.45)$, the SRMR was low enough (0.05), and the CFI (0.96) and NNFI (0.96) were high enough. These values suggested that the full four-factor model could fit the data well. Factor loadings (directional relationships from the social support dimensions to their corresponding items) for all models ranged from 0.49 to 0.90 . Composite reliability, which draws upon the standardized loadings and measurement error for each item (Fornell \& Larcker, 1981; Shook, Ketchen, Hult, \& Kacmar, 2004), was acceptable $(>0.70)$ for the four subscales: emotional 0.77, esteem 0.86, informational 0.73 , and tangible 0.83 (Cronbach's alpha internal reliability coefficients for the four subscales were: emotional 0.77 , esteem 0.85 , informational 0.72 , and tangible 0.83). Means and standard deviations for the four social support subscales (and all other scales used in this study) are shown in Table I.

Correlations between the social support dimensions (inter-subscale correlations based upon composite subscale scores using the raw data) ranged from moderate $(r=0.35, P<0.05)$ to high $(r=0.75$, $P<0.05$ ) (see Table I). Correlations of this magnitude have been noted with other measures (Brookings \& Bolton, 1988; Cohen and Wills, 1985; B. R. Sarason, Sarason, \& Pierce, 1990b). In light of these correlations, we also ran four further models on the social support data using confirmatory factor analysis. First, we tested a single higher-order factor model. This produced a very poor fit. Second, we tested a model with all items loading on a single scale. This also produced a very poor fit. Third, we 
Table I. Means, standard deviations, and intercorrelations of social support, stressors, and GPI.

\begin{tabular}{|c|c|c|c|c|c|c|c|c|c|c|}
\hline & mean $\pm s$ & 1 & 2 & 3 & 4 & 5 & 6 & 7 & 8 & 9 \\
\hline 1. Emotional support & $2.87 \pm 0.70$ & & & & & & & & & \\
\hline 2. Esteem support & $3.09 \pm 0.84$ & $0.75^{*}$ & & & & & & & & \\
\hline 3. Informational support & $2.57 \pm 0.74$ & $0.60^{*}$ & $0.67 *$ & & & & & & & \\
\hline 4. Tangible support & $2.26 \pm 0.92$ & $0.35^{*}$ & $0.42 *$ & $0.61 *$ & & & & & & \\
\hline 5. Technical problems & $2.69 \pm 1.07$ & $-0.21^{*}$ & $-0.19^{*}$ & $-0.04^{*}$ & $0.02 *$ & & & & & \\
\hline 6. Competition pressure & $2.54 \pm 0.90$ & $0.18^{*}$ & 0.14 & $0.22 *$ & $0.29 *$ & $0.26^{*}$ & & & & \\
\hline 7. Personal problems & $2.32 \pm 1.14$ & 0.01 & 0.00 & 0.03 & -0.00 & $0.21 *$ & -0.05 & & & \\
\hline 8. Total social support & $2.70 \pm 0.65$ & $0.80^{*}$ & $0.86^{*}$ & $0.87^{*}$ & $0.75^{*}$ & $-0.12 *$ & $0.26^{*}$ & 0.01 & & \\
\hline 9. Total stressors & $2.52 \pm 0.68$ & -0.03 & -0.03 & 0.09 & 0.13 & $0.76^{*}$ & $0.55^{*}$ & $0.65^{*}$ & 0.06 & \\
\hline 10. GPI & $0.70 \pm 3.08$ & $-0.41^{*}$ & $-0.47^{*}$ & $-0.39 *$ & $-0.30 *$ & $0.37^{*}$ & -0.09 & $0.28^{*}$ & $-0.48^{*}$ & $0.31 *$ \\
\hline
\end{tabular}

*Correlation significant at 0.05 level (two-tailed).

tested a two-factor model that combined emotional and esteem support on the one hand and informational and tangible support on the other (cf. Cutrona \& Russell, 1990). This fit was markedly better than that for the previous two models but still well outside the values outlined in $\mathrm{Hu}$ and Bentler (1999). Fourth, we tested a two-factor model of tangible support on the one hand and a combined scale including emotional, esteem, and informational support on the other. This produced the best of these four models, although the fit statistics $\left(\chi^{2}\right.$ $(89)=156.43, P=0.00$; RMSEA $=0.08, \mathrm{SRMR}=$ $0.07, \mathrm{CFI}=0.91, \mathrm{NNFI}=0.90)$ were still outside the values outlined in $\mathrm{Hu}$ and Bentler (1999) and worse than the original four-factor model. At this point, a chi-square difference test (e.g. Tabachnick \& Fidell, 1996) revealed that the fit of this more parsimonious model was significantly worse $\left(\chi^{2}\right.$ $(5)=44.74, P<0.01)$ than the four-factor model.

The items on the emotional support subscale were: "cheered you up"; "helped you to relax when you felt under pressure"; "helped take your mind off things"; "given you moral support when you felt down". The items on the esteem support subscale were: "told you, you can do it"; "encouraged you"; "believed in you"; "reassured you". The items on the informational support subscale were: "helped put things into perspective"; "given you advice about coping"; "given you constructive criticism"; "helped you prepare mentally". The items on the tangible support subscale were: "helped to set up sessions in practice"; "helped plan your practice to deal with problems"; "helped organize practice and competitions".

Effects of stressors, social support dimensions, and products on GPI

The results of the moderated hierarchical regression analyses are shown in Table II. There were significant main effects for stressors upon GPI in four of the six models tested. Over and above the variance accounted for by stressors, there were significant main effects for social support upon GPI in all six models tested. All these results were in the hypothesized direction, with stressors associated with worse performance and social support associated with better performance. None of the interactions (stress-buffering effects) added significantly to the variance of GPI explained by the main effects of the stressors and social support.

At this point, we ran an additional set of regression analyses (Table III). There were two reasons for this. First, the correlations between the social support dimensions were relatively high (see Table I), and the results of the confirmatory factor analyses demonstrated reasonable fit statistics for alternatives to the four-factor support model. Second, the pattern of results suggested that the support dimensions were not associated with differential effects upon GPI. The following additional models were specified: (a) a combination of models 1 and 2 (involving the stressor "technical problems with your game"), models 3 and 4 (involving the stressor "personal problems"), and models 5 and 6 (involving the stressor "competition pressure"); (b) a model with all stressors and all social support dimensions; and (c) a model with a combined score for stressors (labelled "total stress") and a combined score for support (labelled "total social support"). The results from these models suggest that esteem support may be the key social support dimension predicting GPI. The results also suggest that a combined score for stressors and a combined score for social support capture the essence of this study's results equally well.

\section{Discussion}

The results of this study suggest that the influence of received social support upon performance is positive, but that in this study the support functioned as a main effect, not a stress-buffer. Unlike the study of Rees and Hardy (2004), the matching of specific support dimensions with specific stressors did not 
Table II. Results of moderated hierarchical regression analyses: Effects of stressors, social support, and products upon GPI ( $n=117)$.

\begin{tabular}{|c|c|c|c|c|c|c|}
\hline Dependent variable & Independent variable & $\Delta R^{2 \mathrm{a}}$ & $\Sigma R^{2 \mathrm{~b}}$ & $P(F)^{\mathrm{c}}$ & $b^{\mathrm{d}}$ & $P(t)^{\mathrm{e}}$ \\
\hline \multirow[t]{3}{*}{ GPI } & Technical problems with your game & 0.13 & 0.13 & 0.00 & 1.09 & 0.00 \\
\hline & Informational support & 0.14 & 0.27 & 0.00 & -1.15 & 0.00 \\
\hline & Product & 0.00 & 0.27 & 0.71 & 0.10 & 0.71 \\
\hline \multirow[t]{3}{*}{ GPI } & Technical problems with your game & 0.13 & 0.13 & 0.00 & 1.14 & 0.00 \\
\hline & Tangible support & 0.10 & 0.23 & 0.00 & -0.96 & 0.00 \\
\hline & Product & 0.00 & 0.23 & 0.94 & 0.02 & 0.94 \\
\hline \multirow[t]{3}{*}{ GPI } & Personal problems & 0.08 & 0.08 & 0.00 & 0.86 & 0.00 \\
\hline & Emotional support & 0.17 & 0.25 & 0.00 & -1.25 & 0.00 \\
\hline & Product & 0.01 & 0.26 & 0.23 & -0.28 & 0.23 \\
\hline \multirow[t]{3}{*}{ GPI } & Personal problems & 0.08 & 0.08 & 0.00 & 0.86 & 0.00 \\
\hline & Esteem support & 0.22 & 0.30 & 0.00 & -1.46 & 0.00 \\
\hline & Product & 0.00 & 0.30 & 0.86 & 0.04 & 0.86 \\
\hline \multirow[t]{3}{*}{ GPI } & Competition pressure & 0.01 & 0.01 & 0.35 & -0.04 & 0.88 \\
\hline & Emotional support & 0.16 & 0.17 & 0.00 & -1.26 & 0.00 \\
\hline & Product & 0.00 & 0.17 & 0.65 & 0.13 & 0.65 \\
\hline \multirow[t]{3}{*}{ GPI } & Competition pressure & 0.01 & 0.01 & 0.35 & -0.06 & 0.82 \\
\hline & Esteem support & 0.22 & 0.23 & 0.00 & -1.45 & 0.00 \\
\hline & Product & 0.00 & 0.23 & 0.94 & -0.02 & 0.94 \\
\hline
\end{tabular}

Note: All variables standardized except for product. Product was formed from the two preceding (standardized) variables.

${ }^{\mathrm{a}}$ Stepwise change in $R^{2} .{ }^{\mathrm{b}}$ Cumulative $R^{2}$. ${ }^{\mathrm{c}}$ Probability of $F$ for $\Delta R^{2}$. ${ }^{\mathrm{d}}$ Unstandardized regression coefficient in final equation. ${ }^{\mathrm{e}}$ Probability of $t$ for $b$.

Table III. Results of moderated hierarchical regression analyses: Effects of stressors, social support, and products upon GPI $(n=117)$.

\begin{tabular}{|c|c|c|c|c|c|c|}
\hline Dependent variable & Independent variable & $\Delta R^{2 \mathrm{a}}$ & $\Sigma R^{2 \mathrm{~b}}$ & $P(F)^{\mathrm{c}}$ & $b^{\mathrm{d}}$ & $P(t)^{\mathrm{e}}$ \\
\hline \multirow[t]{3}{*}{ GPI } & Technical problems with your game & 0.13 & 0.13 & 0.00 & 1.09 & 0.00 \\
\hline & Informational support & 0.15 & 0.28 & 0.00 & -0.91 & 0.00 \\
\hline & Tangible support & & & & -0.40 & 0.20 \\
\hline \multirow[t]{3}{*}{ GPI } & Personal problems & 0.08 & 0.08 & 0.00 & 0.86 & 0.00 \\
\hline & Emotional support & 0.23 & 0.31 & 0.00 & -0.36 & 0.32 \\
\hline & Esteem support & & & & -1.18 & 0.00 \\
\hline \multirow[t]{3}{*}{ GPI } & Competition pressure & 0.01 & 0.01 & 0.35 & -0.04 & 0.88 \\
\hline & Emotional support & 0.22 & 0.23 & 0.00 & -0.36 & 0.36 \\
\hline & Esteem support & & & & -1.18 & 0.00 \\
\hline \multirow[t]{7}{*}{ GPI } & Technical problems with your game & 0.21 & 0.21 & 0.00 & 0.84 & 0.00 \\
\hline & Personal problems & & & & 0.70 & 0.00 \\
\hline & Competition pressure & & & & -0.15 & 0.56 \\
\hline & Informational support & 0.18 & 0.39 & 0.00 & -0.34 & 0.36 \\
\hline & Tangible support & & & & -0.32 & 0.30 \\
\hline & Emotional support & & & & -0.11 & 0.77 \\
\hline & Esteem support & & & & -0.84 & 0.03 \\
\hline \multirow[t]{2}{*}{ GPI } & Total stressors & 0.10 & 0.10 & 0.00 & 1.04 & 0.00 \\
\hline & Total social support & 0.24 & 0.34 & 0.00 & -1.53 & 0.00 \\
\hline
\end{tabular}

Note: All variables standardized.

${ }^{\mathrm{a}}$ Stepwise change in $R^{2} .{ }^{\mathrm{b}}$ Cumulative $R^{2}$. ${ }^{\mathrm{C}}$ Probability of $F$ for $\Delta R^{2}$. ${ }^{\mathrm{d}}$ Unstandardized regression coefficient in final equation. ${ }^{\mathrm{e}}$ Probability of $t$ for $b$.

lead to stress-buffering in the present study. Although the optimal matching hypothesis offers an eloquent explication of when buffering is likely to occur, its empirical support base is still mixed (Burleson, 2003). It may be that detection of stressbuffering effects is more likely with process-related assessments of performance, rather than performance outcome (Rees \& Hardy, 2004).
Evans (1985) noted that significant moderator effects are notoriously difficult to detect, while McClelland and Judd (1993) highlighted a number of statistical factors that contribute to the difficulty in finding significant interactions in field studies compared with experimental studies. Failure to find stress-buffering (interactive) effects of social support has also been attributed to sample size issues 
(Wills \& Shinar, 2000). In the present study, the sample size of 117 should be sufficient to detect medium effect sizes (cf. Cohen, 1992), but it is still relatively small, a natural function of the lack of highcalibre golfers. If one were to use a lower standard of golfer, then one could more easily increase sample size, but well-designed studies of high-level performers are relatively rare. It is also unlikely that social support would have such a strong effect on the performance of recreational golfers. Krause (1995) suggested that failure to find buffering effects may be due to a misspecified relationship between social support and stress - social support may only be beneficial up to a point, beyond which it may exacerbate the effects of stress. Following the procedures outlined by Krause, we also tested for non-linear interactions with the present data, but again none were significant. Finally, it may simply be that this set of results supports the empirical literature (if not the theory): perceived support (and not received support) is most consistently linked with stress buffering (Cohen, 1988; Cohen et al., 2000; Cohen \& Wills, 1985; Wills \& Shinar, 2000).

In this study, received social support aided performance, regardless of the amount of stress. The additional set of regression analyses highlighted that esteem support may be the principal dimension in this regard. It also highlighted that by combining stressors and social support, the essence of this study's results was captured equally well. Although researchers argue that, at a conceptual level, social support may still be broken down into dimensional components (Cohen \& Wills, 1985; Cutrona \& Russell, 1990), this result suggests that in relation to their performance golfers may not distinguish among types of stressors and types of support.

A further speculative explanation for this pattern of results may be offered. There were significant main effects for social support upon performance and significant main effects for stressors. Entered first, the effect of the stressors upon performance was in a negative direction. Over and above the variance in performance explained by the stressors, social support explained a further (and generally greater) amount of variance in a positive direction. Thus, the receipt of social support may have offset the negative impact of the stressors. Veiel (1992) implied that buffering is present when social support is beneficial in some proportion to exposure to stress, and Wheaton (1985) described these "borderline" (p. 359) stress-buffering cases as independent distress deterrent models. According to Wheaton, while social support "can be seen as directly counterbalancing the impact of stress" (p. 359), counterbalancing is not buffering. He nonetheless added that this should not detract from the relevance of social support in impacting upon outcomes. On the contrary, he wrote, "in fact, resources in an independent distress deterrent role may ultimately have more to do with the reduction of illness or distress than resources only in a stress-buffering role" (p. 360). In a sense, main effects are more important, because they always offer benefit.

A particular strength of this study was the proportion of variance in performance explained by the main effects of social support. These main effects ranged from $10 \%$ to $24 \%$ (medium to large effect sizes, cf. Cohen, 1992) for effects on performance, compared with values of $3 \%$ to $10 \%$ in the Rees and Hardy (2004) study and $12 \%$ to $21 \%$ in the Rees et al. (1999) study. These effect sizes are greater than the fairly modest effect sizes observed in two recent meta-analyses of the relationships of anxiety and self-confidence with performance (Craft, Magyar, Becker, \& Feltz, 2003; Woodman \& Hardy, 2003). Although we acknowledge that there is variability in the performance/outcome measures used across studies, we make this point because anxiety and self-confidence are considered key variables in sport psychology that have been studied extensively. On the other hand, research on social support in sport is scarce and has generally been limited to its influence on sport injury (for reviews, see Bianco \& Eklund, 2001; Brewer, 2001; Hardy, Burke, \& Crace, 1999; Udry, 1996; Williams, 2001). The results of the present study offer a very powerful indication of the impact social support may have in relation to sports performance.

In conclusion, we have provided further insight into the potential for social support to positively influence performance. To develop our understanding further, in future researchers might include measures of both perceived and received support to help elucidate whether perceived support is indeed more likely to lead to stress buffering than received support (Wills \& Shinar, 2000). A key area is to examine the mechanisms through which perceived and received support exert their effects (see Lakey \& Cohen, 2000). For example, effects upon performance outcome might be mediated by selfconfidence and self-efficacy, or by performance processes, such as increased positive affect and flow (cf. Cohen, 1988; Rees and Hardy, 2004; Rees et al., 1999). Finally, it should be noted that we did not assess stressors and social support experienced during actual competition, so future research might consider such assessment using different methods.

\section{References}

Aldwin, C. M. (1994). Stress, coping, and development: An integrative perspective. New York: Guilford Press.

Bandura, A. (1997). Self-efficacy: The exercise of control. New York: Freeman. 
Baron, R. M., \& Kenny, D. A. (1986). The moderator-mediator variable distinction in social psychological research: Conceptual, strategic, and statistical considerations. Fournal of Personality and Social Psychology, 51, 1173-1182.

Barrera, M. J. (1986). Distinctions between social support concepts, measures, and models. American fournal of Community Psychology, 14, 413-445.

Bentler, P. M. (1990). Comparative fit indexes in structural models. Psychological Bulletin, 103, 411-423.

Bianco, T., \& Eklund, R. C. (2001). Conceptual considerations for social support research in sport and exercise settings: The case of sport injury. Fournal of Sport and Exercise Psychology, 23, $85-107$.

Biddle, S. J. H., Markland, D., Gilbourne, D., Chatzisarantis, N. L. D., \& Sparkes, A. (2001). Research methods in sport and exercise psychology: Quantitative and qualitative issues. fournal of Sports Sciences, 19, 777-809.

Brewer, B. W. (2001). Psychology of sport injury rehabilitation. In R. N. Singer, H. A. Hausenblas, \& C. M. Janelle (Eds.), Handbook of sport psychology (2nd edn., pp. 787-809). New York: Wiley.

Brookings, J. B., \& Bolton, B. (1988). Confirmatory factor analysis of the Interpersonal Support Evaluation List. American fournal of Community Psychology, 16, 137-147.

Burleson, B. R. (2003). Emotional support skill. In J. O. Greene and B. R. Burleson (Eds.), Handbook of communication and social interaction skills (pp. 551-594). Mahwah, NJ: Erlbaum.

Cohen, J. (1992). A power primer. Psychological Bulletin, 112, $155-159$.

Cohen, S. (1988). Psychosocial models of the role of social support in the etiology of physical disease. Health Psychology, 7, 269-297.

Cohen, S., Gottlieb, B. H., \& Underwood, L. G. (2000). Social support and health. In S. Cohen, L. G. Underwood, \& B. H. Gottlieb (Eds.), Social support measurement and intervention: A guide for health and social scientists (pp. 3-25). New York: Oxford University Press.

Cohen, S., Underwood, L. G., \& Gottlieb, B. H. (Eds.) (2000). Social support measurement and intervention: $A$ guide for health and social scientists. New York: Oxford University Press.

Cohen, S., \& Wills, T. A. (1985). Stress, social support and the buffering hypothesis. Psychological Bulletin, 98, 310-357.

Craft, L. L., Magyar, T. M., Becker, B. J., \& Feltz, D. L. (2003). The relationship between the Competitive State Anxiety Inventory-2 and sport performance: A meta-analysis. fournal of Sport and Exercise Psychology, 25, 44-65.

Crocker, P. R. E. (1992). Managing stress by competitive athletes: Ways of coping. International Fournal of Sport Psychology, 23, $161-175$.

Cutrona, C. E., \& Russell, D. W. (1990). Type of social support and specific stress: Toward a theory of optimal matching. In B. R. Sarason, I. G. Sarason, \& G. R. Pierce (Eds.), Social support: An interactional view (pp. 319-366). New York: Wiley.

Dunkel-Schetter, C., \& Bennett, T. L. (1990). Differentiating the cognitive and behavioral aspects of social support. In B. R. Sarason, I. G. Sarason, \& G. R. Pierce (Eds.), Social support: An interactional view (pp. 267-296). New York: Wiley.

Evans, M. G. (1985). A Monte Carlo study of the effects of correlated method variance in moderated multiple regression analysis. Organizational Behavior and Human Decision Processes, $36,305-323$.

Fornell, C., \& Larcker, D. F. (1981). Evaluating structural equation models with unobservable variables and measurement error. Fournal of Marketing Research, 18, 39-50.

Gould, D., Guinan, D., Greenleaf, C., Medbery, R., \& Peterson, K. (1999). Factors affecting Olympic performance: Perceptions of athletes and coaches from more and less successful teams. The Sport Psychologist, 13, 371-394.
Gould, D., Jackson, S. A., \& Finch, L. M. (1993a). Life at the top: The experiences of U.S. National Champion figure skaters. The Sport Psychologist, 7, 354-374.

Gould, D., Jackson, S. A., \& Finch, L. M. (1993b). Sources of stress in national champion figure skaters. Fournal of Sport and Exercise Psychology, 15, 134-159.

Gould, D., Petlichkoff, L., Simons, J., \& Vevera, M. (1987). Relationship between Competitive State Anxiety Inventory-2 subscale scores and pistol shooting performance. Fournal of Sport Psychology, 9, 33-42.

Gould, D., Tuffey, S., Udry, E., \& Loehr, J. (1996). Burnout in competitive junior tennis players: II: Qualitative analysis. The Sport Psychologist, 10, 341-366.

Hanton, S., Fletcher, D., \& Coughlan, G. (2005). Stress in elite sports performers: A comparative study of competitive and organizational stressors. Fournal of Sports Sciences, 23, 11291141.

Hardy, C. J., Burke, K. L., \& Crace, R. K. (1999). Social support and injury: A framework for social support-based interventions with injured athletes. In D. Pargman (Ed.), Psychological bases of sport injuries (2nd edn., pp. 175-198). Morgantown, WV: Fitness Information Technology.

Hardy, C. J., \& Crace, R. K. (1991). Social support within sport. Sport Psychology Training Bulletin, 3, 1-8.

Helgeson, V. S. (1993). Two important distinctions in social support: Kind of support and perceived versus received. fournal of Applied Social Psychology, 23, 825-845.

Holt, N. L., \& Hogg, J. M. (2002). Perceptions of stress and coping during preparations for the 1999 women's soccer World Cup finals. The Sport Psychologist, 16, 251-271.

House, J. S., \& Kahn, R. L. (1985). Measures and concepts of social support. In S. Cohen \& S. L. Syme (Eds.), Social support and health (pp. 83-108). New York: Academic Press.

Hu, L., \& Bentler, P. M. (1999). Cutoff criteria for fit indexes in covariance structure analysis: Conventional criteria versus new alternatives. Structural Equation Modeling, 6, 1-55.

Jaccard, J., Turrisi, R., \& Wan, C. K. (1990). Interaction effects in multiple regression (Quantitative Applications in the Social Sciences \#72). Newbury Park, CA: Sage.

Jones, G. (1995). More than just a game: Research developments and issues in competitive anxiety in sport. British fournal of Psychology, 86, 449-478.

Jöreskog, K. G. (1993). Testing structural equation models. In K. A. Bollen \& J. S. Long (Eds.), Testing structural equation models (pp. 294-316). Newbury Park, CA: Sage.

Jöreskog, K. G., \& Sörbom, D. (1993). LISREL 8 user's reference guide. Chicago, IL: Scientific Software International.

Krause, N. (1995). Assessing stress-buffering effects: A cautionary note. Psychology and Aging, 10, 518-526.

Lakey, B., \& Cohen, S. (2000). Social support theory and measurement. In S. Cohen, L. G. Underwood, \& B. H. Gottlieb (Eds.), Social support measurement and intervention: $A$ guide for health and social scientists (pp. 29-52). New York: Oxford University Press.

Leventhal, E. A., Suls, J., \& Leventhal, H. (1993). Hierarchical analysis of coping: Evidence from Attention and Avoidance (edited by H. W. Krohne) (pp. $71-99)$. Seattle, WA: Hogrefe \& Huber.

Madden, C. C., Kirkby, R. J., \& McDonald, D. (1989). Coping styles of competitive middle distance runners. International Fournal of Sport Psychology, 20, 287-296.

McCaffrey, N., \& Orlick, T. (1989). Mental factors related to excellence among top professional golfers. International fournal of Sport Psychology, 20, 256-278.

McClelland, G. H., \& Judd, C. M. (1993). Statistical difficulties of detecting interactions and moderator effects. Psychological Bulletin, 114, 376-390. 
Rees, T., \& Hardy, L. (2000). An investigation of the social support experiences of high-level sports performers. The Sport Psychologist, 14, 327-347.

Rees, T., \& Hardy, L. (2004). Matching social support with stressors: Effects on factors underlying performance in tennis. Psychology of Sport and Exercise, 5, 319-337.

Rees, T., Hardy, L., Ingledew, D. K., \& Evans, L. (2000). Examination of the validity of the social support survey in confirmatory factor analysis. Research Quarterly for Exercise and Sport, 71, 322-330.

Rees, T., Ingledew, D. K., \& Hardy, L. (1999). Social support dimensions and components of performance in tennis. fournal of Sports Sciences, 17, 421-429.

Richman, J. M., Hardy, C. J., Rosenfeld, L. B., \& Callanan R. A. E. (1989). Strategies for enhancing social support networks in sport: A brainstorming experience. fournal of Applied Sport Psychology, 1, 150-159.

Rosenfeld, L. B., \& Richman, J. M. (1997). Developing effective social support: Team building and the social support process. Fournal of Applied Sport Psychology, 9, 133-153.

Sarason, B. R., Sarason, I. G., \& Pierce, G. R. (1990a). Social support: An interactional view. New York: Wiley.

Sarason, B. R., Sarason, I. G., \& Pierce, G. R. (1990b). Traditional views of social support and their impact on assessment. In B. R. Sarason, I. G. Sarason, \& G. R. Pierce (Eds.), Social support: An interactional view (pp. 9-25). New York: Wiley.

Sarason, I. G., Sarason, B. R., \& Pierce, G. R. (1990). Social support, personality and performance. Fournal of Applied Sport Psychology, 2, 117-127.

Scanlan, T. K., Stein, G. L., \& Ravizza, K. (1991). An in-depth study of former elite figure skaters: III. Sources of stress. fournal of Sport and Exercise Psychology, 13, 103-120.

Schutz, R. W., \& Gessaroli, M. E. (1993). Use, misuse, and disuse of psychometrics in sport psychology research. In R. N. Singer, M. Murphey, \& L. K. Tennant (Eds.), Handbook of research on sport psychology (pp. 901-917). New York: Macmillan.

Shook, C. L., Ketchen, D. J., Jr., Hult, G. T. M., \& Kacmar, K. M. (2004). An assessment of the use of structural equation modeling in strategic management research. Strategic Management fournal, 25, 397-404.
Steiger, J. H. (1990). Structural model evaluation: An interval estimation approach. Multivariate Behavioral Research, 25, $173-180$.

Tabachnick, B. G., \& Fidell, L. S. (1996). Using multivariate statistics. New York: HarperCollins.

Tucker, L. R., \& Lewis, C. (1973). A reliability coefficient for maximum likelihood factor analysis. Psychometrika, 38, 110.

Udry, E. (1996). Social support: Exploring its role in the context of athletic injuries. Fournal of Sport Rehabilitation, 5, 151163.

Veiel, H. O. F. (1992). Some cautionary notes on buffer effects. In H. O. F. Veiel \& U. Baumann (Eds.), The meaning and measurement of social support (pp. 273-289). New York: Hemisphere.

Veiel, H. O., \& Baumann, U. (Eds.) (1992). The meaning and measurement of social support. New York: Hemisphere.

Watson, D., \& Pennebaker, J. W. (1989). Health complaints, stress, and distress: Exploring the central role of negative affectivity. Psychological Review, 96, 234-254.

Weinberg, R. S. (1990). Anxiety and motor performance: Where to go from here? Anxiety Research, 2, 227-242.

Wethington, E., \& Kessler, R. C. (1986). Perceived support, received support and adjustment to stressful life events. Fournal of Health and Social Behavior, 27, 78-89.

Wheaton, B. (1985). Models for the stress-buffering functions of coping resources. Fournal of Health and Social Behavior, 26, $352-364$.

Williams, J. M. (2001). In R. N. Singer, H. A. Hausenblas, \& C. M. Janelle (Eds.), Handbook of sport psychology (2nd edn., pp. 766-786). New York: Wiley.

Wills, T. A., \& Shinar, O. (2000). Measuring perceived and received social support. In S. Cohen, L. G. Underwood, \& B. H. Gottlieb (Eds.), Social support measurement and intervention: A guide for health and social scientists (pp. 86-135). New York: Oxford University Press.

Woodman, T., \& Hardy, L. (2003). The relative impact of cognitive anxiety and self-confidence upon sport performance: A meta-analysis. Fournal of Sports Sciences, 21, 443-457. 